\title{
Pemetaan Industri di Kota Batam Menggunakan Mobile GIS Berbasis Android
}

\author{
Zaki A Agha ${ }^{1 *}$, Andy Triwinarko ${ }^{2 *}$, Baigo Hamuna ${ }^{3 * *}$ \\ * Teknik Informatika, Politeknik Negeri Batam \\ **Universitas Cenderawasih \\ zakiaagha@gmail.com ${ }^{1}$, andy@ polibatam.ac.id ${ }^{2}$, bhamuna@ polibatam.ac.id ${ }^{2}$
}

\begin{tabular}{l}
\hline Article Info \\
\hline Article history: \\
Received 31-02-2017 \\
Revised 20-03-2017 \\
Accepted 27-03-2017 \\
\hline
\end{tabular}

Keyword:

Industry, GeoServer, Mobile GIS, Android.

\begin{abstract}
Android-based mobile GIS application is a service that combines digital maps in vector and smartphone media to search industry in Batam. This application is online. Currently, the information presented only provide location of region, users who are not familiar with the location will be difficult or take a long time to find the location of industry. Therefore it is necessary to design an application that is able to provide information on the location of industries in Batam. This thesis did research and development of Android-based mobile GIS applications to provide information on the location of industry in Batam. These applications have been built with the ability to show a map of Batam are taken from GeoServer, handle the search process, displays information and maps location of industry as desired user.
\end{abstract}

\section{Pendahuluan}

Kebutuhan informasi telah menjadi kebutuhan pokok masyarakat Indonesia tidak terkecuali masyarakat Kota Batam. Kota Batam merupakan lingkungan kerja daerah industri dengan didukung oleh Otorita Pengembangan Daerah Industri Kota Batam atau lebih dikenal dengan Badan Pengusahaan Batam (BP Batam) sebagai penggerak pembangunan Kota Batam. Secara umum industri di Kota Batam terbagi menjadi industri berat dan industri ringan. Industri berat didominasi oleh industri galangan kapal, industri fabrikasi, industri baja, industri logam dan lainnya. Sedangkan industri ringan meliputi industri manufacturing, industri elektronik, industri garment, industri plastik dan lainnya. Pemetaan industri perlu diterapkan untuk mengetahui lokasi industri yang ada di Kota Batam. Sistem informasi geografis (bahasa Inggris: Geographic Information System disingkat GIS) dapat mengatasi masalah tersebut. GIS menampilkan letak lokasi industri pada kondisi sesungguhnya. Informasi pemetaan industri di Kota Batam yang ada saat ini hanya menyedikan lokasi perkawasan. Sehingga ketika pengguna ingin mencari informasi industri tertentu tidak bisa ditangani sistem yang ada. Oleh karena itu perlu dibuat sebuah aplikasi yang mampu menampilkan informasi mengenai lokasi industri yang ada di Kota Batam.
Metode pemetaan bereferensi geografis seperti GIS Berbasis Dekstop Untuk Sentra Industri Kerajinan Bantul Yogyakarta [1], GIS Berbasis Web Untuk Pemetaan Industri Kecil di Kabupaten Bantul [2] banyak diusulkan oleh peneliti. Mobile GIS memiliki kelebihan bisa digunakan dimana saja, bisa dipadukan dengan GPS, sistem koleksi data sangat efisien yaitu dengan "point and click", dan data spasial dikelola dalam dataset referensi. Tetapi mobile GIS memiliki kelemahan pengaksesan terhadap data GIS dan fungsifungsinya tidak selengkap dan sekomplek di desktop.

Pada penelitian ini menerapkan mobile GIS untuk pemetaan industri, sehingga hasil pemetaan dapat digunakan sebagai referensi untuk mengetahui informasi dan lokasi industri tertentu. Mobile GIS nantinya menampilkan dalam bentuk informasi berbasis platform android, sehingga mudah diakses dari smartphone.

\section{LANDASAN TEORI}

\section{A. Sistem Informasi Geografis (SIG)}

ESRI (Environmental System Research Institute) mendefinisikan SIG adalah kumpulan yang terorganisir dari perangkat keras komputer, perangkat lunak, data geografi dan personil yang dirancang secara efisien untuk memperoleh, 
menyimpan, meng-update, memanipulasi, menganalisis dan menampilkan semua bentuk informasi yang bereferensi geografis. Pengertian SIG dapat beragam tetapi mempunyai satu kesamaan, yaitu bahwa SIG adalah suatu sistem yang berkaitan dengan informasi geografis. Dalam arti yang lebih sempit, SIG merupakan suatu sistem berbasis komputer yang digunakan untuk menyimpan dan menganalisis objek-objek dan fenomena-fenomena dengan lokasi geografis merupakan karakteristik yang penting untuk dianalisis. Berdasarkan teknologi dan informasinya, SIG dapat dikategorikan dalam tiga aplikasi, yaitu: SIG berbasis desktop (Desktop GIS), SIG berbasis web (Web GIS), dan SIG berbasis Mobile (Mobile GIS). Meskipun demikian, ketiganya saling berhubungan satu dengan yang lainnya [3].

Mobile GIS merupakan integrasi antara teknologi perangkat mobile, Global Positioning System (GPS) dan wireless communication untuk mengakses internet GIS. Kombinasi dari beberapa teknologi tersebut membuat mobile GIS dapat digunakan untuk menangkap, menyimpan, update, manipulasi, analisis dan menampilkan informasi geografi secara tepat. Sehingga melalui teknologi tersebut juga dapat membuat basis data yang diakses oleh personil di lapangan secara langsung di segala tempat dan waktu. Sistem ini dapat menambah informasi secara real-time ke basis data dan aplikasinya dalam hal kecepatan akses, tampilan, dan penentuan keputusan. Secara singkat Mobile GIS didefinisikan sebagai sebuah integrasi cara kerja perangkat lunak/keras untuk pengaksesan data dan layanan geospasial melalui perangkat bergerak via jaringan kabel atau nirkabel [3].

\section{B. Geoserver}

Geoserver adalah suatu open source software yang ditulis menggunakan Bahasa Pemrograman Java, memungkinkan pengguna untuk melakukan sharing dan editing terhadap data geospatial. Geoserver sendiri menggunakan standar dari Open Geospatial Consortium (OGC). Geoserver memudahkan dalam pembuatan peta dan spatial data sharing. Geoserver meyediakan data geospasial melalui layanan web dan dapat diakses melalui layanan protocol HTTP, aplikasi pemetaan online (MapServer, Google Maps, Google Earth, Yahoo Maps, dan Microsoft irtual Earth), dan aplikasi desktop (ArcGIS, WMS/WFS Client).

\section{Analisis Perancangan}

Analisis perancangan sistem diilustrasikan pada gambar 1, bahwa pengguna bisa mencari lokasi industri yang tersebar di Kota Batam berdasarkan kata kunci nama industri. Kemudian system dapat mencari data industri pada database server. Selanjutnya sistem dapat menampilkan peta lokasi dan informasi pendukung lainnya seperti alamat, latitude, longitude, dan produk industri.

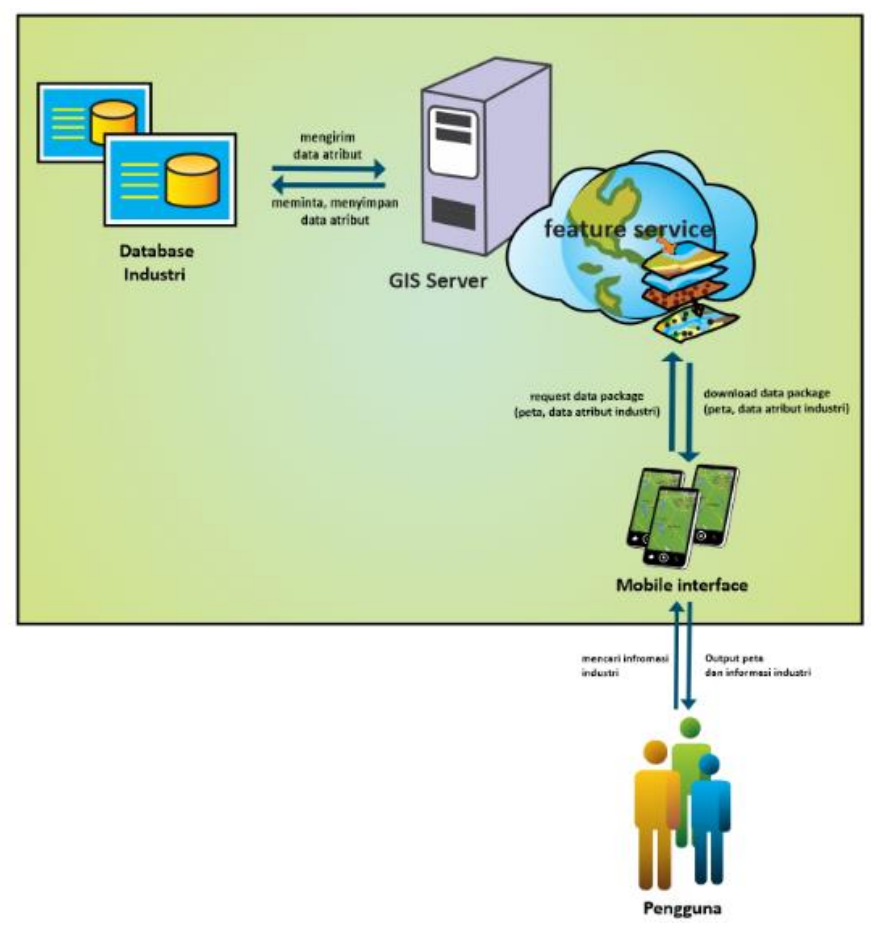

Gambar 1. Deskripsi Umum Sistem.

Data-data yang diperlukan dalam pelaksanaan penelitian adalah sebagai berikut:

1) Data koordinat GPS tiap lokasi industri diperoleh melalui pengukuran GPS.

2) Data industri diperoleh dari buku Profil Industrial Estate Batam yang diterbitkan oleh Batam Indonesia Free Zone Authority (BIFZA) 2012 dan hasil survei lapangan

Aplikasi mobile GIS pemetaan industri di Kota Batam dirancang agar dapat digunakan oleh pengguna sebagai sarana untuk mengetahui informasi tentang industri serta dapat menampilkan lokasi industri tersebut, informasi spasial yang dibuat terdiri dari beberapa layer, yaitu:

1) Peta Kecamatan, layer ini berisikan peta Kota Batam.

2) Peta Jalan, layer ini memuat jalan yang ada di Kota Batam.

3) Peta Kawasan, layer ini berisi kawasan industri yang tersebar di Kota Batam.

4) Peta Industri, layer lokasi berisi titik lokasi yang ada di Kota Batam

TABEL I

DATA PETA

\begin{tabular}{|l|l|l|}
\hline No & Nama & Sumber \\
\hline 1 & Peta Kecamatan & Hasil digitasi \\
\hline 2 & Peta Kawasan & Hasil digitasi \\
\hline 3 & Peta Jalan & Hasil digitasi \\
\hline 4 & Peta Industri & Hasil digitasi \\
\hline
\end{tabular}


Entity Relationship Diagram (ER-D) merepresentasikan secara grafis hubungan antar entitas dapat dilihat pada Gambar 2.

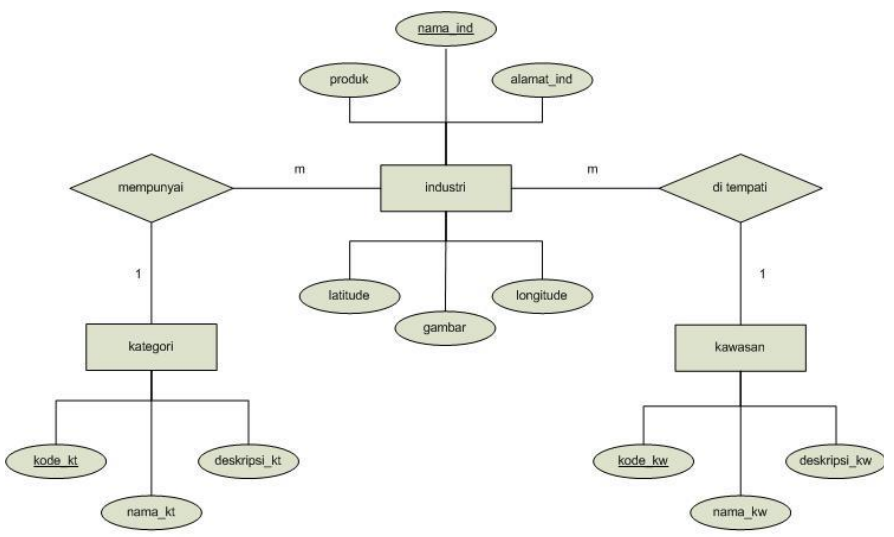

Gambar 2. Entity Relationship Diagram.

Pada gambar 2 menunjukkan bahwa setiap industri (yang terdiri dari nama_ind merupakan nama dari industri, alamat_ind merupakan alamat industri, produk, gambar, latitude dan longitude) memiliki satu kategori (kode_kt, nama_kt merupakan nama kategori, dan deskripsi_kt untuk deskripsi singkat tentang kategori) dan menempati suatu Kawasan (yang terdiri dari kode_kw, nama_kw merupakan nama dari Kawasan, dan deskripsi_kw untuk diskripsi singkat dari kawasan).

Relasi antar tabel menunjukkan tabel-tabel yang saling berelasi, tabel industri berelasi dengan tabel kawasan yang berfungsi untuk menentukan suatu industri berada kawasan tertentu, tabel industri juga berelasi dengan tabel kategori untuk menentukan setiap industri memiliki kategori tertentu (industri manufacturing, industri elektronika, industri garment, industri plastik dan lainnya).

\section{IMPLEMENTASI DAN PENGUJIAN}

Setelah dilakukan tahap perancangan, maka tahap selanjutnya adalah implementasi dan pengujian pada perangkat lunak. Implementasi akan menghasilkan aplikasi yang dapat dijalankan di lingkungan operasional. Untuk mengetahui apakah aplikasi tersebut dapat melakukan fungsi sesuai deskripsi perencanaan maka perlu dilakukan pengujian. Adapun fungsi yang akan diuji pada Mobile GIS berbasis android pemetaan industri di Kota Batam sesuai dengan analisis kebutuhan fungsionalitas adalah sebagai berikut:

1) Melakukan pencarian industri berdasarkan nama industri

2) Menampilkan informasi detail industri dari hasil pencarian

3) Menampilkan peta lokasi industri dari hasil pencarian

Data yang digunakan diperoleh dari hasil perancangan, disimpulkan kebutuhan beberapa peta yaitu peta kecamatan, kawasan, jalan dan industri. Pengolahan data dilakukan dengan proses digitasi dan penambahan atribut menggunakan perangkat lunak QGIS 2.6.0. Data yang digunakan pada sistem ini merupakan hasil digitasi peta kota Batam.

Dalam sistem ini beberapa data yang akan diolah adalah data dalam format shp, karena dapat langsung dimanfaatkan oleh geoserver. Tentu saja semua data tersebut tidak langsung digunakan, tetapi perlu dilakukan penyesuaian dahulu baik mengenai jenis data, atribut yang ada, sampai proses penggabungan data. Oleh karena itu, perlu dilakukan pemrosesan data awal (preprocessing).
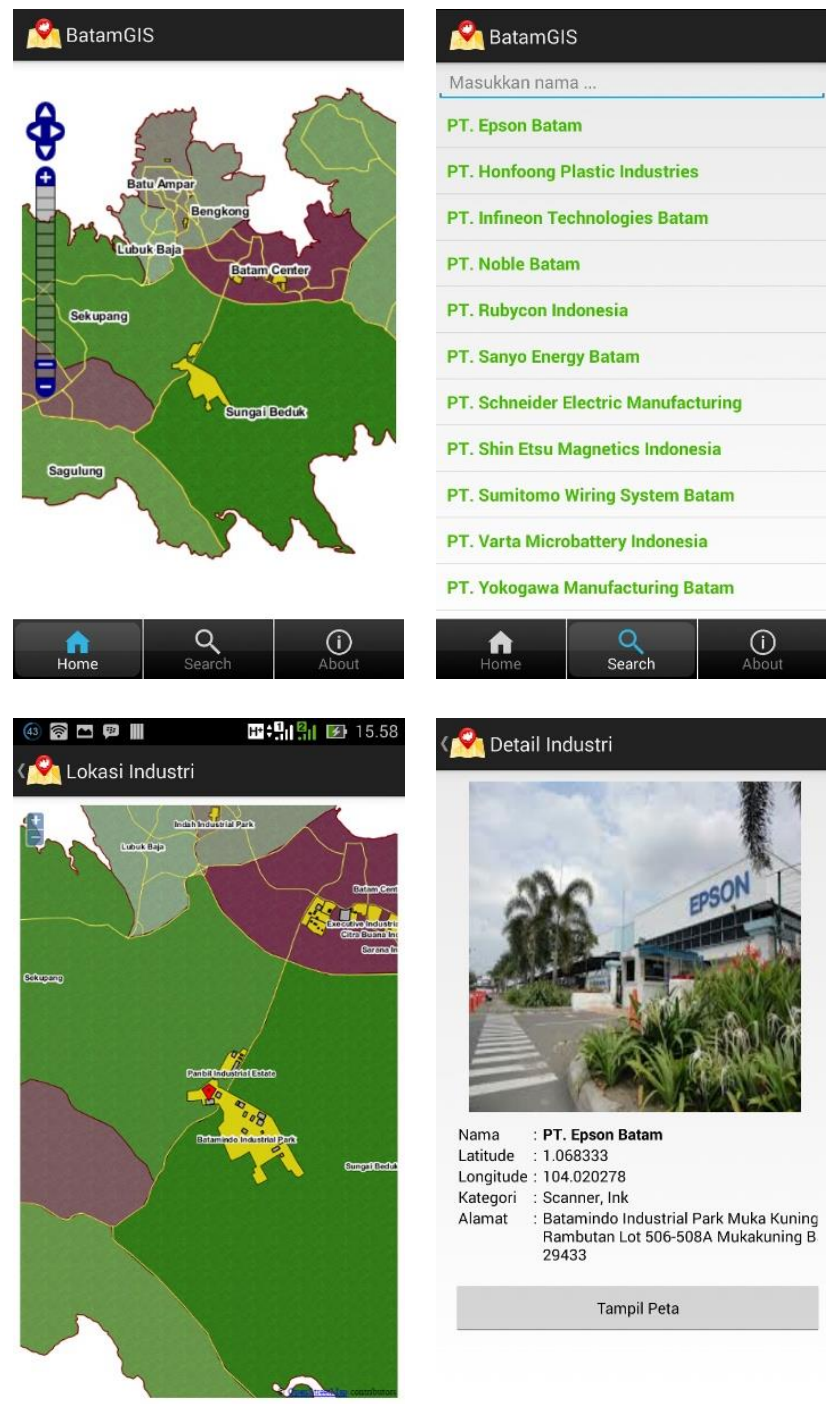

Gambar 3. Halaman Antar Muka Mobil GIS Industri Batam.

Pada antarmuka halaman awal aplikasi mobile GIS ini terdapat beberapa gambaran mengenai logo aplikasi dan beberapa button penghubung ke halaman-halaman berikutnya seperti button pencarian, about, dan bantuan. Halaman ini adalah halaman utama dari aplikasi mobile GIS berbasis android pemetaan industri di Kota Batam dapat dilihat pada 
gambar 3. Setelah pengguna dihadapkan pada antarmuka halaman utama aplikasi mobile GIS, pengguna dapat memilih button pencarian. Pada halaman ini digunakan untuk melakukan pencarian industri berdasarkan kata kunci yang dimasukkan oleh pengguna. Setelah itu, pengguna akan dihadapkan pada halaman baru ketika pengguna memilih atau me-klik data industri hasil pencarian. Pada halaman ini terdiri detail informasi industri. Pengguna bisa menampilkan lokasi industri dari hasil pencarian. Pengguna memilih button view on map di halaman detail industri untuk menampilkan lokasi industri tersebut. Berikut adalah rancangan tampilan lokasi industri.

\section{Penutup}

Berdasarkan analisis, perancangan dan hasil implementasi diperoleh kesimpulan sebagai berikut.

1. Aplikasi mobile GIS berbasis android berhasil didesain dan dibangun untuk mencari lokasi dan menampilkan informasi industri yang dituju.

2. Aplikasi mobile GIS berbasis android berhasil diimplementasikan untuk menampilkan informasi industri yang ada di Kota Batam.

\section{DAFTAR PUSTAKA}

[1] W.N.M. Sari, "Membangun Aplikasi Sistem Informasi Geografis Berbasis Desktop Untuk Sentra Industri Kerajinan Bantul Yogyakarta," Naskah Publikasi, Sekolah Tinggi Manajemen Informatika dan Komputer, AMIKOM, Yogyakarta, 2010.

[2] B.M. Jati, "Sistem Informasi Geografis Berbasis Web Untuk Pemetaan Industri Kecil di Kabupaten Bantul," Skripsi, UIN Sunan Kalijaga, 2011.

[3] R. Riyanto, "Sistem informasi geografis berbasis mobile", Yogyakarta: Gava Media, 2010

[4] H. Safaat, Nazruddin, "Android Pemrograman Aplikasi Mobile Smartphone dan Tablet PC Berbasis Android," Bandung: Informatika, 2012.

[5] SKPD Kota Batam, 2012, Dinas Kependudukan dan Catatan Sipil Pemerintah Kota Batam.

[6] GeoServer. [Online]. Tersedia: http://geoserver.org/

[7] R. Thiede, T. Sutton, H. Düster, M. Sutton, "Quantum GIS Training Manual Release 1.0," 2014.

[8] Wroclawski Serge, 2010, OpenStreetMap for Web Developers, Website: http://www.emacsen.net/osm/osm-web-tutorial.pdf

[9] D. E. Kurniawan, "Aplikasi Kamus Aneka Bahasa Daerah Berbasis Smartphone Android," Seminar Nasional Teknologi Informasi, Komunikasi dan Industri (SNTIKI), 2013.

[10] Android Developer, 2014, "Saving Data in SQL Databases", Website: http://developer.android.com/training/basics/datastorage/databases.html.

[11] D. E. Kurniawan, "Pemetaan Jalur Transportasi Bus Umum Kota Batam Menggunakan QuantumGIS dan Geoserver," Jurnal Teknologi dan Sistem Informasi, 2(2), 1-8, 2016.

[12] D. Rethans, 2011, "Geolocation and Maps with PHP", Website: http://derickrethans.nl/talks/maps-tek11.pdf 